\title{
The Role of Actigraphy to Identify Sleep Disorders in Children with ADHD
}

\author{
Checa-Ros Ana ${ }^{1,2^{*}}$, Vargas-Pérez $\mathbf{M}^{2}$, Muñoz-Gallego $\mathrm{A}^{3}$, Molina-Carballo $\mathrm{A}^{2}$, Uberos-Fernández $\mathrm{J}^{2}$ and Muñoz-Hoyos $\mathrm{A}^{2}$ \\ ${ }^{1}$ School of Medicine of Granada, San Cecilio University Hospital, Spain \\ ${ }^{2}$ Department of Pediatrics, University of Granada, San Cecilio Hospital, Spain \\ ${ }^{3}$ Department of Language and Computer Science, University of Málaga, Spain \\ *Corresponding author: Checa Ros Ana, paediatric resident at San Cecilio University Hospital, Doctor Oloriz Street, 1, Granada-18012, Spain, Tel: 958-023-996; E- \\ mail: anaxeca@hotmail.com
}

Received date: July 23, 2014; Accepted date: September 06, 2014; Published date: September 10, 2014

Copyright: (C) 2014 Ana CR, et al. This is an open-access article distributed under the terms of the Creative Co mmons Attribution License, which permits unrestricted use, distribution, and reproduction in any medium, provided the original author and source are credited.

\begin{abstract}
Currently sleep disorders are one of the most prevalent problems in children, with an estimated prevalence of $15-20 \%$ and a highly variable clinical spectrum. One of the pathologies in which sleep disorders achieve special relevance is in attention-deficit and hyperactivity disorder (ADHD), because the complex association between these two phenomena can largely determine the therapeutic handling and prognosis of these patients. Nowadays, the number of research articles that makes unquestionable the relation between ADHD and sleep disorders is increasing, as well as studies in which actigraphy acquires increasingly validity as a tool to asses sleep in the paediatric population, with a good correlation with polysomnography, considered the "gold standard" in sleep medicine. Our review aims to highlight the positive impact that the use of actigraphy as a screening tool for the detection of sleep problems in ADHD may have on the quality of life of these children and their families. After an exhaustive review of the most recent published literature on this topic, we suggest a set of recommendations which are summarized in that the actigraphy allows us to study longer periods of sleep-wake in an stable way, avoiding the difficulties of polysomnographic studies in children. All this makes it an ideal screening element in the initial assessment of patients with ADHD who report sleep problems.
\end{abstract}

Keywords: Actigraphy; Sleep disorders; Attention deficit and hyperactivity disorder; Pediatric population

\section{Introduction}

According to recent data, sleep disorders in children are one of the most prevalent problems found by paediatricians in their daily clinical practice, accounting for $15-20 \%$ of the general population and with an apparently growing incidence according to different references. Generally, in children under the age of 5 , it is estimated that $30 \%$ have sleep disturbances of various kinds [1], and a review of several studies shows that between 13 and $27 \%$ of parents of children from 4 to 12 years relate the presence of sleep difficulties of varying magnitude. Most of these difficulties corresponding to poor sleep hygiene, bedtime resistance, anxiety at the time of going to sleep, delayed sleep onset, reactive co-sleeping, snoring , enuresis, nocturnal awakenings, parasomnias, nightmares, night terrors, sleepwalking, early morning awakening and excessive daytime sleepiness [1].

These problems are usually stable throughout childhood, so that a child with sleep difficulties at 8 months probably will still display at 3 years, and those who exhibited them at 2 years will follow present in adolescence. Among the long-term consequences of disturbed sleep patterns have been included physical stunting, behavioural and performance problems in school, family and social disruption, etc. [2], problems that must be related in some way to the maturation of central nervous system. Any disturbance of the normal sleep development could lead to neurodevelopmental disorders [3].

Despite this, there are relatively few longitudinal studies that examine sleep development in children within their own home environment [4], since most studies are conducted in sleep laboratories, only during night periods [5]. In this sense, actigraphy provides an useful tool over other methods of evaluation of sleep/wake cycle that allows a continuous noninvasive evaluation and that can be used for extended periods of time in the child's environment [6].

Over the last two decades, actigraphy has become one of the main tools in sleep medicine, as can be seen in the growing number of publications including actigraphy compared to them that include polysomnography (PSG) (ratio 1:10 actigraphy-PSG in 1991 compared to a ratio of 1:4 in 2009) [7]. The recent reviews and clinical guidelines introduced by the American Sleep Disorders Association (ASDA) have established actigraphy as a method of valid and reliable assessment in specific domains of research in sleep medicine $[8,9]$.

One of the fields of child neurology where sleep disorders acquires a great interest is in attention-deficit and hyperactivity disorder (ADHD), which is one of the most common childhood behavioural disorders, with an estimated prevalence of $5 \%$ in school children [10]. In these patients, complaints about sleep problems are very common, reaching up to $55 \%$ of cases according to Corkum et al. [11].

Fortunately, the relationship between ADHD and sleep disorders has recovered interest in the last 5-10 years, after having been overlooked for years by researchers and clinicians in this field. Progress in this knowledge area can have a great impact on the daily clinical practice: 1). On the one hand, the management of sleep problems in children with ADHD could significantly reduce the severity of behavioural symptoms and improve quality of life for these children and their families [12]. 2). On the other hand, take into consideration sleep disturbances may also be critical in the evaluation and treatment of children who are sent for consultation with problems 
of inattention, hyperactivity and/or impulsivity but do not meet diagnostic criteria for ADHD according to DSM -IV.

In fact, it has been pointed out that any sleep disturbance resulting in inadequate duration, interrupted or fragmented sleep, or excessive daytime sleepiness can lead or contribute to behaviour or attention problems [12]. Thereby at least in one sample of patients with inattention, hyperactivity and/or impulsivity, these symptoms can be improved or even eliminated after the primary sleep problem has been corrected.

\section{Material and Methods}

Our purpose is to outline, through a literature review, the importance of actigraphy as an essential tool for the study of sleep medicine, both in adults and especially in children, and its value not only diagnostic but also therapeutic and prognostic.

For that we have consulted databases "PubMed", "ScienceDirect" and "Scopus". Using keywords as "actigraphy", "sleep disorders", "attention deficit and hyperactivity disorder" and "pediatric population", we have selected the most current articles about this issue.

In this article we review the role of actigraphy in sleep medicine and particularly in paediatric settings, its applicability for detecting altered patterns of sleep/wake in children with ADHD and the implication that this may have on treatment, monitoring and the final prognosis of these patients.

\section{Fundaments of actigraphy}

Actigraphy is a technique that consists in recording the movements. It is based on the employ of similar devices to a wristwatch usually placed on the non-dominant wrist (although they can also be placed in ankle or the trunk). This device monitors the movements for extended periods time, so that scores or scales of activity obtained (in periods of 1 minute, for example) are transferred to scales of sleep/wake based on computerized algorithms. The latest models of actigraphs incorporate other complementary registration procedures, as a photometric system, which quantifies the amount of existing light, or a thermometric system, which allows studying the temperature fluctuations and their correlation with activity, being a parameter for chronobiological studies.

Actimeters are connected by a suitable interface to a computer with the appropriate signal treatment programs, allowing the display of records, analysis and reproduction by printer. There are several models on the market, each one has its own characteristics and requires appropriate measurement algorithms for categorizing sleep/ wake and validation studies [7]. There may be artefacts that alter the results of actigraph in the determinations of the sleep/wake cycle, such as a failure to record the movements, postures that block arm movements, the breathing movements themselves and the external movement caused by the normal use of vehicles.

\section{Reliability and validity of actigraph}

The reliability and validity of actigraphy to detect the sleep-wake cycle has been established by previous studies, especially in a normal population of children and adults [8]. However, this is less clear in research on specific populations or specific devices [13,14], in which some authors conclude that the very low ability of actigraph to detect awakenings questions its validity for measuring sleep quality in clinical populations with interrupted sleep. For example, Sitnick et al. [14] compared minute by minute the sleep-wake scores based on actigraphy and videosomnography in young people, collecting an percentage of agreement of $94 \%$, a sensitivity of $97 \%$ (percentage of sleep minutes identified by PSG which are collected as such by actigraphy) and a specificity of $24 \%$ (rate of wake minutes collected by PSG which are identified as such by actigraphy). De Souza et al. [15] also provided relatively low percentages of specificity (34-44\%). On the other hand, the review of Tryon [16] illustrated that the validity of actigraphy is acceptable compared to many other medical tests. He also indicated that the discrepancy PSG-actigraphy should be attributed to the accuracy of PSG, being part thereof predictable and correctable.

Recent studies in the context of the child population, such as Gnidovec and Hyde ones [17,18], reflect low percentages of specificity (between 39.4 and 68.9\%). However they conclude that actigraphy is a reliable method for the assessment of sleep in children. This validity is also present in the case of children with intellectual and motor deficits [19].

Another aspect that requires attention in the validation studies of actigraphy compared to PSG is that these studies are based, almost without exception, in the period of "time in bed" (usually in sleep laboratories). However the main advantage of actigraphy is its ability to document sleep-wake patterns continuously over a 24 hour period over days. Therefore, the validation studies should also allow a comparison of long periods in and out of the bed with long periods of wakefulness [7].

There is a frequent comparison between data provided by actigraphy and data provided by subjective measures, such as daily sleep records reported by parents and caregivers. So et al. [6] compared the two methods in a sample of 20 infants during the first year of life. They found a good relationship between both methods, although the data from parental sleep diaries overestimated the nocturnal sleep time compared with actigraphy. Similar results have been reported in other studies that have worked with an older child population [20]. Another interesting issue is the stability of actigraphic measurements over time, both in adult and paediatric population. According to this, Sadeh et al. [21] confirmed a significant stability of actigraphic measures which were compared annually during early adolescence, despite the maturational changes in sleep patterns that occur in this age period.

Regarding data analysis, a new approach to modern actigraphy has been introduced by Sazonov et al. [22]. In their study, the device was placed in the diaper collecting similar rates of validity in comparison to those who placed the device in the ankle. Enomoto et al. [23] also provided similar results with the placement of a new device on the wrist. Chae et al. [24] have reevaluated specific criteria for sleep onset detected by actigraphy. They define it as 5 minutes of inactivity to achieve a better correlation between PSG and actigraphy in the data referring to sleep onset latency (SOL), total sleep time (TST) and wake after sleep onset (WASO). This is a change with regard to the criteria used previously (e.g., 10 or 15 minutes of immobility).

\section{Actigraphic detection of sleep disorders}

Regarding the assessment of insomnia, several studies have concluded that actigraphy is a sensitive tool to detect differences between groups of individuals with insomnia and control population. However, the discrepancies found between actigraphy and subjective 
assessments of patients could be attributed, among other factors, to the fact that actigraphy overestimates sleep time, because of the efforts of patients with insomnia for remaining immobile in bed during long periods of time $[25,26]$.

One of recent applications of actigraphy has been the detection of periodic limb movements during sleep (PLMS) using a high-resolution model (e.g. every 5 seconds), and comparing data of electromyography (EMG) with data derived from a simultaneous study PSG-actigraphy. Sforza et al [27] showed the highest correlation between actigraphy and PSG in detecting movements, although actigraphy underestimated electromyographic activity of legs. This problem could be partially solved with the use of a new device designed especially for detection of periodic limb movements during sleep with a high time resolution [28]. However, the application in children ages 4 to 12 years [29] has not demonstrated acceptable validity.

As regards sleep-disordered breathing (SDB), results indicate that the estimated total sleep time provided by actigraph improved the validity of apnea-hypopnea index (AHI) compared to the results based on the simple polygraph [30]. In addition, actigraphy can also be used to assess efficacy of treatment with nasal continuous positive airway pressure (nCPAP) [31].

Although less common, actigraphy can also help in the diagnosis of narcolepsy, apart from detecting the behavioural changes induced by sleep deprivation as an essential part in the evaluation of patients with narcolepsy [32].

Recent studies, such as Sivertsen et al. [33], Manber et al. [34], Espie et al. [35] and Harris et al. [36] have highlighted the actigraphy potential to assess the change in sleep patterns in response to cognitive behavioural therapy conducted in patients with insomnia. It is appreciated an improvement in the subjective perception of these patients regarding their sleep pattern.

In this context, actigraphy has also often been used to evaluate the effects of pharmacological interventions for sleep problems $[8,37]$. Actigraphy has proved to be sensitive enough to detect secondary changes to such interventions. So, in different studies, the effects of temazepam in patients with insomnia have been evaluated [38]. Also the effects of melatonin and zopiclone have been tested in patients with inadequate sleep patterns [39]. In this research line, an interesting study about the effect of melatonin in patients with cystic fibrosis was conducted by De Castro-Silva et al. [40] and was published in the Journal of Pineal Research in 2010. In this study, 20 patients with cystic fibrosis were randomized to receive placebo or melatonin for 21 days. They were monitored with actigraphy 6 days before starting treatment and on the third day of the same. It was showing an improvement in the efficiency and sleep duration.

\section{Use of actigraphy in pediatric population}

Based on all that has been explained before, we deduce that actigraphy can be a method particularly valid in children, because the fact that the information provided by the parents as the only source of information can limit the accuracy of the knowledge that we have about children sleep [41]. According to the increasing use of actigraphy in this knowledge area, a significant increase in the number of studies conducted on actigraphy in children is observed (Figure 1). We can emphasize the fact that the number of published studies in 2010 is similar to the total of published studies between 1991 and 2001.

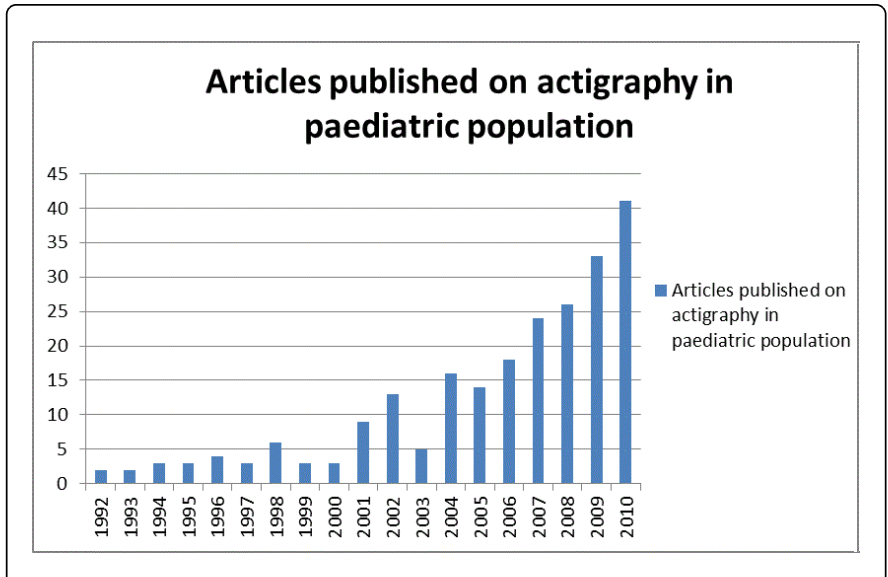

In 2007 the American Academy of Sleep Medicine established that "Actigraphy is indicated for delineating sleep patterns, and to document treatment responses in normal infants and children (in whom traditional sleep monitoring by polysomnography can be difficult to perform and/or interpret), and in special paediatric populations" [42]. Despite this recommendation, nowadays there is not standardized practices regarding collection parameters and scoring actigraphic signals, so we want to make some recommendations as to the paediatric population is concerned.

As regards the choice of actigraph, we must consider the type of device (warranty, battery, maintenance, software program associated and support service), and if it fits in size, weight and comfort with the age the child population of the study [41].

Regarding study design, we need to take into account how the actigraph will be delivered and collected, as well as the time required for data collection. The actigraph usually requires to be placed a minimum of 7 nights [43], and even sometimes 2 weeks if the detected differences between weekdays and weekend are of interest. In addition, variables to be evaluated should be selected a priori, deciding who will fill out sleep diary (parent, child ...), the frequency with which sleep diary will be completed and the format of a diary (paper, electronic, phone call ...) [41].

In terms of managing data, sleep diary should be used to reduce the frequency of artefacts (movements of device, prolonged periods of low activity, periods of activity that should be recognized as sleep or nighttime awakenings movements that may be due to bed sharing, and any cause of atypical sleep as an intercurrent disease, fever ...) [41]; on the other hand, it is also necessary to select the scoring algorithms and the threshold level for awakening depending on the kind of study population and previously published studies [41]. Authors should include in their research articles not just the way they handled the data, but also the missing data and rules of coding and processing of data [41].

In this context, Meltzer et al. [41] proposed a list of data to be recorded in this research area using actigraphy in paediatric population (Table 1). Their study was published in 2012 in Sleep Medicine Reviews. 


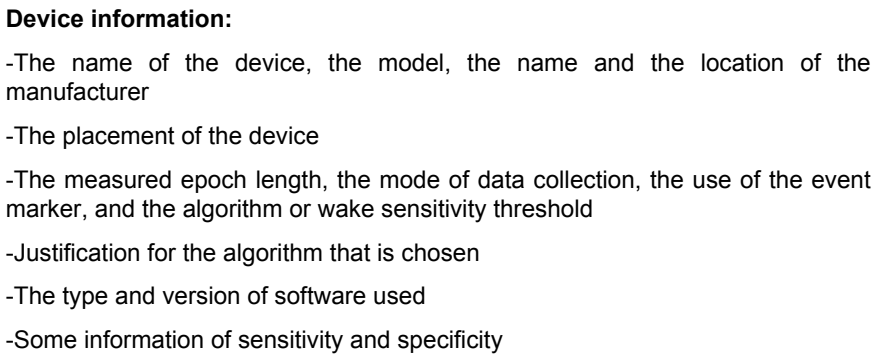

-The name of the device, the model, the name and the location of the manufacturer

-The placement of the device

-The measured epoch length, the mode of data collection, the use of the event marker, and the algorithm or wake sensitivity threshold

-Justification for the algorithm that is chosen

-The type and version of software used

-Some information of sensitivity and specificity

\section{Sleep diary:}

-Type of sleep diary used (paper, electronic, telephone call)

-The person who completed sleep diary (parent, child)

-Frequency of diary completion (at bedtime only, morning and evening)

Data collection and processing (including missing data):

-Number of nights of data collection

-Number of weekday and weekend nights (if relevant)

-Methods used to identify and handle artifact

-Number of lost data due to technical failure, participant non-adherence, artifact

\section{Data variables:}

-Clear definition of the variables, including ones automatically calculated by manufacturer scoring programs (sleep bouts, wake bouts, motionless sleep or immobile time, circadian parameters)

-Clear definition of the scoring rules used, using common/standardized names

Table 1: Standard offer of information to including in the literature of investigation of the paediatric dream with actigraphy.

\section{Discussion}

Despite what some clinicians may think, the available evidence suggests that drugs for attention-deficit and hyperactivity disorder (ADHD) are just one of the possible causes of sleep problems associated with it. Children with ADHD exhibit significantly more sleep disorders compared with their controls regardless of the medication used. We can include among these disorders: bedtime resistance, sleep-onset difficulties, and night awakenings, difficulties with morning awakenings, sleep-disordered breathing, and daytime sleepiness [44]. Several studies suggest that sleep disorders affect more than $50 \%$ of children affected by ADHD. In our article we briefly describe the major sleep disorders and their association with ADHD in order to get an idea of the importance of this relationship.

A literature review of 2005 [45] concluded that up to $44 \%$ of patients with ADHD suffered from restless legs syndrome (RLS) or similar symptoms, and $26 \%$ of subjects with RLS had symptoms of ADHD . Although data are probably overestimated, and causality of this association is not well defined, from a clinical point of view the RLS may exacerbate ADHD symptoms. In addition, children with RLS can develop resistance to bedtime, since they associate this time with unpleasant sensations of RLS. Parents may interpret this refusal as an expression of their general oppositional behaviour [46], ignoring the sleep disturbance. On the other hand, ADHD may worsen symptoms of RLS, as proposed by Chervin et al [47] and Wagner et al [48]. Therefore, the RLS should be systematically investigated in children with ADHD or symptoms similar thereto.

Another sleep disturbance described in children with ADHD is periodic limb movements during sleep (PLMS). Huang et al. found that $10.2 \%$ of patients with ADHD suffered from this disorder compared with $0 \%$ of controls [49]. This association was subsequently confirmed by Bruni et al. [50].

It has been reported that children with $\mathrm{ADHD}$ without medication and sleep-onset insomnia (SOI) exhibit a delay in the evening peak melatonin secretion [51], so it has been hypothesized that the sleeponset insomnia in these children could be due to a circadian rhythm alteration [52]. This could contribute to bedtime resistance and discomfort symptoms during sleep, which may be erroneously considered as an expression of their general behaviour disorder [46]. Therefore, the rate of melatonin secretion should be studied in children with ADHD and sleep-onset insomnia and/or resistance to bedtime.

Excessive nocturnal motor activity (arms or legs) has been documented also by actigraphy in children with ADHD [52,53]. It was subsequently confirmed by an infrared camera [54], although this has not led to differences in polysomnographic recordings.

The relationship between sleep-disordered breathing (SDB) and ADHD is not well established [47]. Chervin states that the values of AHI (apnea-hypopnea index) obtained in children with ADHD (1 to 5), although not very high, they are suggestive of paediatric obstructive sleep apnea and require medical attention.

Moreover, we should not forget the impact that psychiatric comorbidity with ADHD (such as oppositional disorder, anxiety disorders, learning disorders, various behavioural disorders, tics and Tourette's syndrome [55]) and/or the treatments used for the same, may have on sleep disturbance as a causal factor to consider adding. This is demonstrated in a recent article published by Moreau et al. in 2013. They collected 41 children diagnosed with ADHD between 6 and 13 years, compared those without psychiatric comorbidity with those who showed it, and they observed a higher percentage of sleep disturbances in the latter [56].

It has also suggested that stimulant drugs used as treatment of ADHD can negatively influence on sleep, due to its "rebound" effect (intensification of the symptoms of ADHD when drug effect disappears). Results of different studies are opposing [56,57] and it seems that vulnerability to these negative effects can be probably related to individual factors such as Brown and McMullen said [58]. In this context it seems appropriate to quote an article published in 2014, consisting of a meta-analysis that included 393 patients with ADHD who were randomized to either methylphenidate versus placebo. They monitored data using actigraphy and they founded a significant reduction in total sleep time in patients who received methylphenidate [59].

\section{Results}

After all this, there is a clear need to investigate sleep disorders in all children referred for consultation for possible ADHD, as an appropriate management of sleep problems in these children may improve both quality of life and their families. Moreover, more studies are considered necessary to investigate this association, and where actigraphy acquires an important role as a primary screening test.

The main conclusions that can be deduced from this review are:

- Sleep disorders have become one of the emerging problems in childhood, reaching a prevalence of 15 to $20 \%$, with a course that tends to be stable with the child's age. 
- The ADHD and sleep disorders association is increasingly recognized. Although its genesis is multifactorial and still not fully clear, has great potential impact on the prognosis and quality of life of these patients and their families.

- The actigraphy is now a valid and reliable method to assess sleep, which correlates well with PSG in the normal population and in specific populations. Its application in paediatric population allows us to study sleep-wake patterns over long periods with great stability in their measurements and avoiding the difficulties of polysomnographic studies in children.

- Using actigraphs in patients with ADHD who report sleep problems as a method of screening and initial evaluation of these alterations could reconsider the management and treatment of these children, with a positive influence in their prognosis.

\section{References}

1. Working Group on Clinical Practice Guide to Sleep Disorders in Children and Adolescents in Primary Care (2011) Clinical Practice Guide of Sleep Disorders in Children and Adolescents in Primary Care. Quality Plan for the National Health System of the Ministry of Health, Social Policy and Equality. Unit Health Technology Assessment Agency Lain Entralgo; Clinical Practice Guides in the NHS: UETS No 2009/8

2. Owens JA, Witmans M (2004) Sleep problems. Curr Probl Pediatr Adolesc Health Care 34: 154-179.

3. Kohyama J (1998) Sleep as a window on the developing brain. Curr Probl Pediatr 28: 69-92.

4. Jenni OG, Borbély AA, Achermann P (2004) Development of the nocturnal sleep electroencephalogram in human infants. Am J Physiol Regul Integr Comp Physiol 286: R528-538.

5. Anders T, Sadeh A, Apparedy V (1995) Normal sleep in neonates and children. In: R Ferber and M Kryger (Edn) Principles and Practice of Sleep Medicine in the Child. WB Saunders Co., Philadelphia: 7-18.

6. So K, Adamson TM, Horne RS (2007) The use of actigraphy for assessment of the development of sleep/wake patterns in infants during the first 12 months of life. J Sleep Res 16: 181-187.

7. Sadeh A (2011) The role and validity of actigraphy in sleep medicine: An update. Sleep Medicine Reviews 15: 259-267.

8. Sadeh A, Hauri PJ, Kripke DF, Lavie P (1995) The role of actigraphy in the evaluation of sleep disorders. Sleep 18: 288-302.

9. Sadeh A, Acebo C (2002) The role of actigraphy in sleep medicine. Sleep Med Rev 6: 113-124.

10. Polanczyk G, de Lima MS, Horta BL, Biederman J, Rohde LA (2007) The worldwide prevalence of ADHD: a systematic review and metaregression analysis. Am J Psychiatry 164: 942-948.

11. Corkum P, Tannock R, Moldofsky H (1998) Sleep disturbances in children with attention-deficit/hyperactivity disorder. J Am Acad Child Adolesc Psychiatry 37: 637-646.

12. Owens JA (2005) The ADHD and sleep conundrum: a review. J Dev Behav Pediatr 26: 312-322.

13. Insana SP, Gozal D, Montgomery-Downs HE (2010) Invalidity of one actigraphy brand for identifying sleep and wake among infants. Sleep Med 11: 191-196.

14. Sitnick SL, Goodlin-Jones BL, Anders TF (2008) The use of actigraphy to study sleep disorders in preschoolers: some concerns about detection of nighttime awakenings. Sleep 31: 395-401.

15. de Souza L, Benedito-Silva AA, Pires ML, Poyares D, Tufik S, et al. (2003) Further validation of actigraphy for sleep studies. Sleep 26: 81-85.

16. Tryon WW (2004) Issues of validity in actigraphic sleep assessment Sleep 27: 158-165.

17. Gnidovec B, Neubauer D, Zidar J (2002) Actigraphic assessment of sleepwake rhythm during the first 6 months of life. Clin Neurophysiol 113 1815-1821.
18. Hyde M, O'Driscoll DM, Binette S, Galang C, Tan SK, et al. (2007) Validation of actigraphy for determining sleep and wake in children with sleep disordered breathing. J Sleep Res 16: 213-216.

19. Laakso ML, Leinonen L, Lindblom N, Joutsiniemi SL, Kaski M (2004) Wrist actigraphy in estimation of sleep and wake in intellectually disabled subjects with motor handicaps. Sleep Med 5: 541-550.

20. Holley S, Hill CM, Stevenson J (2010) A comparison of actigraphy and parental report of sleep habits in typically developing children aged 6 to 11 years. Behav Sleep Med 8: 16-27.

21. Sadeh A, Dahl RE, Shahar G, Rosenblat-Stein S (2009) Sleep and the transition to adolescence: a longitudinal study. Sleep 32: 1602-1609.

22. Sazonov E, Sazonova N, Schuckers S, Neuman M; CHIME Study Group (2004) Activity-based sleep-wake identification in infants. Physiol Meas 25: 1291-1304.

23. Enomoto M, Endo T, Suenaga K, Miura N, Nakano Y et al. (2009) Newly developed waist actigraphy and its sleep/wake scoring algorithm. Sleep Biol Rhythms 7: 17-22.

24. Chae KY, Kripke DF, Poceta JS, Shadan F, Jamil SM, et al. (2009) Evaluation of immobility time for sleep latency in actigraphy. Sleep Med 10: 621-625.

25. Lichstein KL, Stone KC, Donaldson J, Nau SD, Soeffing JP, et al. (2006) Actigraphy validation with insomnia. Sleep 29: 232-239.

26. Buysse DJ, Cheng Y, Germain A, Moul DE, Franzen PL, et al. (2010) Night-to-night sleep variability in older adults with and without chronic insomnia. Sleep Med 11: 56-64.

27. Sforza E, Zamagni M, Petiav C, Krieger J (1999) Actigraphy and leg movements during sleep: a validation study. J Clin Neurophysiol 16: 154-160.

28. Sforza E, Johannes M, Claudio B (2005) The PAM-RL ambulatory device for detection of periodic leg movements: a validation study. Sleep Med 6: 407-413.

29. Montgomery-Downs HE, Crabtree VM, Gozal D (2005) Actigraphic recordings in quantification of periodic leg movements during sleep in children. Sleep Med 6: 325-332.

30. Elbaz M, Roue GM, Lofaso F, Quera Salva MA (2002) Utility of actigraphy in the diagnosis of obstructive sleep apnea. Sleep 25: 527-531.

31. Gagnadoux F, Nguyen XL, Rakotonanahary D, Vidal S, Fleury B (2004) Wrist-actigraphic estimation of sleep time under nCPAP treatment in sleep apnoea patients. Eur Respir J 23: 891-895.

32. Middelkoop HA, Lammers GJ, Van Hilten BJ, Ruwhof C, Pijl H, et al. (1995) Circadian distribution of motor activity and immobility in narcolepsy: assessment with continuous motor activity monitoring. Psychophysiology 32: 286-291.

33. Sivertsen B, Omvik S, Havik OE, Pallesen S, Bjorvatn B, et al. (2006) A comparison of actigraphy and polysomnography in older adults treated for chronic primary insomnia. Sleep 29: 1353-1358.

34. Manber R, Edinger JD, Gress JL, San Pedro-Salcedo MG, Kuo TF, et al. (2008) Cognitive behavioral therapy for insomnia enhances depression outcome in patients with comorbid major depressive disorder and insomnia. Sleep 31: 489-495.

35. Espie CA, MacMahon KM, Kelly HL, Broomfield NM, Douglas NJ, et al. (2007) Randomized clinical effectiveness trial of nurse-administered small-group cognitive behavior therapy for persistent insomnia in general practice. Sleep 30: 574-584.

36. Harris J, Lack L, Wright H, Gradisar M, Brooks A (2007) Intensive Sleep Retraining treatment for chronic primary insomnia: a preliminary investigation. J Sleep Res 16: 276-284.

37. Stanley N (2003) Actigraphy in human psychopharmacology: a review. Hum Psychopharmacol 18: 39-49.

38. Wilson SJ, Rich AS, Rich NC, Potokar J, Nutt DJ (2004) Evaluation of actigraphy and automated telephoned questionnaires to assess hypnotic effects in insomnia. Int Clin Psychopharmacol 19: 77-84.

39. Paul MA, Gray G, Sardana TM, Pigeau RA (2004) Melatonin and zopiclone as facilitators of early circadian sleep in operational air transport crews. Aviat Space Environ Med 75: 439-443. 
Citation: Checa-Ros A, Vargas-Pérez M, Molina-Carballo A, Uberos-Fernández J, et al. (2014) The Role of Actigraphy to Identify Sleep Disorders in Children with ADHD . J Metabolic Synd 3: 161. doi:10.4172/2167-0943.1000161

Page 6 of 6

40. de Castro-Silva C, de Bruin VMS, Cunha GMA, Nunes DM, Medeiros CAM et al. (2010) Melatonin improves sleep and reduces nitrite in the exhaled breath condensate in cystic fibrosis - a randomized, double-blind placebocontrolled study. J Pineal Res 48: 65-71.

41. Meltzer LJ, Montgomery-Downs HE, Insana SP, Walsh CM (2012) Use of actigraphy for assessment in pediatric sleep research. Sleep Med Rev 16: 463-475.

42. Morgenthaler T, Alessi C, Friedman L, Owens J, Kapur V, et al. (2007) Practice parameters for the use of actigraphy in the assessment of sleep and sleep disorders: an update for 2007. Sleep 30: 519-529.

43. Acebo C, Sadeh A, Seifer R, Tzischinsky O, Wolfson AR, et al. (1999) Estimating sleep patterns with activity monitoring in children and adolescents: how many nights are necessary for reliable measures? Sleep 22: 95-103.

44. Konofal E, Lecendreux M, Cortese S (2010) Sleep and ADHD. Sleep Med 11: 652-658

45. Cortese S, Konofal E, Lecendreux M, Arnulf I, Mouren MC, et al. (2005) Restless legs syndrome and attention-deficit/hyperactivity disorder: a review of the literature. Sleep 28: 1007-1013.

46. Cortese S, Lecendreux M, Mouren MC, Konofal E (2006) ADHD and insomnia. J Am Acad Child Adolesc Psychiatry 45: 384-385.

47. Chervin RD, Archbold KH, Dillon JE, Pituch KJ, Panahi P, et al. (2002) Associations between symptoms of inattention, hyperactivity, restless legs, and periodic leg movements. Sleep 25: 213-218.

48. Wagner ML, Walters AS, Fisher BC (2004) Symptoms of attentiondeficit/hyperactivity disorder in adults with restless legs syndrome. Sleep 27: 1499-1504.

49. Huang YS, Chen NH, Li HY, Wu YY, Chao CC, et al. (2004) Sleep disorders in Taiwanese children with attention deficit/hyperactivity disorder. J Sleep Res 13: 269-277.

50. Bruni O, Ferri R, Verrillo E, Miano S (2006) New approaches to the study of leg movements during sleep in ADHD children. In: Proceedings of the 20th meeting of the Associated Sleep Societies Sleep 29: 259.
51. Van der Heijden KB, Smits MG, Van Someren EJ, Gunning WB (2005) Idiopathic chronic sleep onset insomnia in attention-deficit/hyperactivity disorder: a circadian rhythm sleep disorder. Chronobiol Int 22: 559-570.

52. Corkum P, Tannock R, Moldofsky H, Hogg-Johnson S, Humphries T (2001) Actigraphy and parental ratings of sleep in children with attention-deficit/hyperactivity disorder (ADHD). Sleep 24: 303-312.

53. Porrino LJ, Rapoport JL, Behar D, Ismond DR, Bunney Jr WE (1983) A naturalistic assessment of the motor activity of hyperactive boys. II. Stimulant drug effects. Arch Gen Psychiatry 40: 688-693.

54. Konofal E, Lecendreux M, Bouvard MP, Mouren-Simeoni MC (2001) High levels of nocturnal activity in children with attention-deficit hyperactivity disorder: a video analysis. Psychiatry Clin Neurosci 55: 97-103.

55. Pliszka S; AACAP Work Group on Quality Issues (2007) Practice parameter for the assessment and treatment of children and adolescents with attention-deficit/hyperactivity disorder. J Am Acad Child Adolesc Psychiatry 46: 894-921.

56. Moreau V, Rouleau N, Morin CM (2014) Sleep of children with attention deficit hyperactivity disorder: actigraphic and parental reports. Behav Sleep Med 12: 69-83.

57. Corkum P, Moldofsky H, Hogg-Johnson S, Humphries T, Tannock R (1999) Sleep problems in children with attention-deficit/hyperactivity disorder: impact of subtype, comorbidity, and stimulant medication. J Am Acad Child Adolesc Psychiatry 38: 1285-1293.

58. Brown TE, McMullen WJ Jr (2001) Attention deficit disorders and sleep/ arousal disturbance. Ann N Y Acad Sci 931: 271-286.

59. De Crescenzo F, Armando M, Mazzone L, Ciliberto M, Sciannamea M, et al. (2014) The use of actigraphy in the monitoring of methylphenidate versus placebo in ADHD: a meta-analysis. Atten Defic Hyperact Disord 6: 49-58. 